\title{
Consideraciones farmacológicas en el manejo anestésico del paciente quemado
}

\author{
RICARDO BUSTAMANTE B. ${ }^{1}$, RENATO CHACÓN A. ${ }^{1}$
}

1 Hospital de Urgencia Asistencia Pública, Clínica Dávila, Universidad de Santiago.

Key words: Muscle relaxants, burns, anesthesia.

Las alteraciones farmacocinéticas y farmacodinámicas presentes en el paciente gran quemado, son uno más de los obstáculos que se debe enfrentar en su manejo clínico. Estas alteraciones deben de ser tenidas en cuenta en la etapa de cuidado crítico, en la terapia analgésica en su período agudo, subagudo y crónico y, por cierto, en el escenario anestésico.

En el ambiente anestésico existen dos hechos que hacen especialmente relevante el conocer estas alteraciones: en primer lugar, el que estos pacientes habitualmente no serán sometidos a una si no a varias anestesias; y en segundo lugar, el que estas anestesias probablemente se distribuirán a lo largo de todo el período del trauma (agudo, subagudo y reparativo).

Esto último es de gran importancia, puesto que las alteraciones hemodinámicas y metabólicas del cuadro, y consecuentemente las farmacocinéticas, atraviesan por períodos con diferentes patrones, a veces opuestos, por lo que en el momento de decidir la conducta anestésica, no sólo se debe tener en cuenta el estado del paciente y la severidad de la quemadura en términos de profundidad y superficie corporal comprometida, sino también, se debe considerar en qué etapa de evolución de su cuadro se encuentra.

Con todo, es necesario señalar que independiente de las múltiples alteraciones que serán descritas a continuación, el paciente gran que- mado puede recibir prácticamente cualquier tipo de anestesia y que todas ellas han demostrado ser efectivas. En consecuencia, las variables que serán detallados más adelante no significan descartar algún tipo de droga o mezcla de drogas, sino adaptar su elección y dosificación a la condición del paciente y a los cambios farmacocinéticos relacionados con el período del cuadro que este cursa.

Excepción a ello lo constituye el manejo de los bloqueadores neuromusculares, que por lejos son el grupo de drogas al que se debe poner mayor atención, puesto que por factores farmacodinámicos relacionados a la estructura del receptor de la placa neuromuscular, su efecto clínico y sus efectos colaterales se encuentran alterados a través de las distintas etapas del cuadro, como será revisado en detalle posteriormente.

\section{Alteraciones hemodinámicas del paciente gran quemado}

El paciente gran quemado, presenta dos estados hemodinámicos bien definidos y contrapuestos: durante las primeras $48 \mathrm{~h}$, se desarrolla un cuadro de shock derivado de hipovolemia y depresión miocárdica ${ }^{1,2}$; en los días posteriores a esas $48 \mathrm{~h}$ iniciales, y siempre que el paciente haya sido resucitado adecuadamente, se desarro-

Correspondencia a:

Dr. Ricardo Bustamante B.

ricardobustamante@vtr.net 
lla un estado circulatorio hiperdinámico acompañado de un síndrome de respuesta inflamatoria sistémica ${ }^{3}$.

Durante las primeras $48 \mathrm{~h}$, existe una severa alteración de la microcirculación, tanto en los tejidos quemados como en los no quemados, lo cual conduce a una masiva extravasación de líquido hacia el espacio intersticial que se edematiza enormemente.

De acuerdo a la ley de Starling, que regula el equilibrio de agua entre el espacio intravascular y el intersticial, en el paciente quemado todos los componentes de la ecuación se encuentran alterados en favor del desplazamiento de líquido hacia este último espacio ${ }^{4}$.

- La permeabilidad capilar se encuentra aumentada debido a la liberación sistémica y local de mediadores inflamatorios.

- La presión hidrostática capilar se encuentra aumentada por dilatación microvascular.

- La presión hidrostática intersticial se encuentra disminuida por destrucción de la matriz de colágeno de los tejidos.

- La presión oncótica capilar se encuentra disminuida por pérdida de proteínas desde el espacio intravascular.

- La presión oncótica intersticial pudiera aumentar por el mismo desplazamiento de proteínas desde el intravascular.

El fenómeno descrito deriva en shock hipovolémico, cuyo manejo exige restitución extremadamente agresiva de volumen a través de fórmulas que son mencionadas en otros artículos de esta revista. En cualquier caso, dicha restitución de volumen, habitualmente en base a cristaloides, acentúa la dilución de proteínas plasmáticas, empeorando el edema tisular.

Al estado hipovolémico descrito, habitualmente se asocia una depresión miocárdica ${ }^{5,6}$ secundaria al efecto de mediadores inflamatorios, entre los que se identifican el factor de necrosis tumoral, interleukina-1 y prostaglandinas ${ }^{7}$, como lo demuestran estudios observacionales con ecocardiografía transesofágica realizados durante las primeras $72 \mathrm{~h}$ desde la quemadura ${ }^{8}$.

La sumatoria de hipovolemia y depresión miocárdica se traduce en disminución del débito cardiaco, aumento de la resistencia vascular sistémica e hipoperfusión tisular².

La inflamación masiva que sigue a las prime- ras $48 \mathrm{~h}$, se caracteriza por un estado hiperdinámico, caracterizado por hipotensión, taquicardia, aumento del débito cardiaco y disminución de la resistencia vascular sistémica.

Se debe tener en cuenta que este cuadro, acompañado de taquipnea, fiebre y leucocitosis, es en todo similar a un shock séptico, pese a que el desarrollo del mismo no implica necesariamente que, a esas alturas, el paciente se encuentre ya infectado.

\section{Insuficiencia renal del paciente gran quemado}

La insuficiencia renal es una complicación frecuente en pacientes quemados, cuya incidencia ha sido reportada hasta en el $40 \%$ de los ca$\operatorname{sos}^{9,10}$.

Esta complicación, relacionada a alta mortalidad $^{11}$, ha sido dividida en dos categorías con etiología diferente ${ }^{12}$ : un cuadro precoz, que se desarrolla dentro de los primeros 5 días desde la injuria y cuyos más probables agentes causales son la hipotensión, hipoperfusión renal y mioglobinuria; y un cuadro tardío, que se instala en forma posterior, en que el principal agente causal involucrado es la sepsis.

\section{Hipermetabolismo del paciente gran quemado}

La principal alteración metabólica posterior a una injuria térmica es una elevación de su tasa, que es proporcional a la superficie corporal comprometida y que se ve influenciada por el manejo del cuadro y la temperatura central del paciente.

Según algunos autores la tasa metabólica se eleva en forma directamente proporcional entre el 30 y el $70 \%$ de superficie corporal quemada ${ }^{13}$, tendiendo este fenómeno a disminuir cuando el tratamiento quirúrgico es agresivo, con escarectomía precoz de la zona dañada.

Por otro lado, se ha descrito un desplazamiento del umbral de control de temperatura central a nivel del hipotálamo, también influenciado por el porcentaje de superficie corporal comprometido, que determina un aumento de la tasa metabólica, tendiente a alcanzar este nuevo estado de equilibrio térmico ${ }^{14}$. 


\section{Consideraciones farmacocinéticas}

Los cambios fisiopatológicos que ocurren con posterioridad a una injuria térmica, alteran parámetros farmacocinéticos como la absorción, biodisponibilidad, unión a proteínas, volumen de distribución y clearance.

Estas alteraciones pueden por un lado ser variables, dependiendo de la fase del cuadro en que se encuentre el paciente y pueden por otro tener efectos dispares, dependiendo de la droga o grupo de drogas analizado.

El estado hemodinámico inicial, en que predomina bajo débito cardiaco, alta resistencia vascular sistémica e hipoperfusión tisular, puede tener consecuencias que son fáciles de deducir: disminución de la absorción y baja biodisponibilidad de drogas administradas por vía diferente a la endovenosa, disminución de la tasa de eliminación de drogas por vía renal y hepática por disminución del flujo sanguíneo a estos órganos y aumento de la velocidad de acumulación y de ascenso de la presión parcial alveolar de los agentes inhalatorios halogenados.

En contrapunto, la fase hemodinámica posterior, caracterizada por un estado hiperdinámico e hipermetabólico, con débito cardiaco alto y resistencias vasculares bajas, se puede asociar a parámetros completamente opuestos: alta absorción y biodisponibilidad desde tejidos como el subcutáneo o intramuscular, aumento del clearance renal y eliminación hepática para algunas drogas y disminución de la tasa de ascenso de la presión parcial alveolar de agentes inhalatorios halogenados.

Más allá de este concepto general, es conveniente analizar algunos de los parámetros farmacocinéticos previamente señalados en forma más detallada:

\section{Unión a proteínas}

La unión a proteínas de una droga influencia directamente su efecto y su tasa de eliminación, ya que es la fracción no unida la que se encuentra disponible para ejercer su efecto en el receptor, para ser filtrada en el glomérulo y para ser metabolizada a nivel hepático.

La albúmina y la glicoproteína alfa1-ácida son las dos proteínas plasmáticas más relevantes desde el punto de vista de su capacidad para unirse drogas, pero presentan características disími- les: mientras la albúmina se une principalmente a drogas ácidas y neutras (diazepam o tiopental), la glicoproteína alfa1-ácida se une a drogas básicas (propanolol o lidocaína).

Por otro lado, además de lo señalado previamente, estas proteínas presentan alteraciones contrapuestas después de una injuria térmica: mientras la albúmina disminuye dramáticamente por los fenómenos descritos previamente en este artículo, la glicoproteína alfa1-ácida, considerada una proteína de fase aguda, eleva sus niveles pudiendo llegar a duplicar su concentración plasmática ${ }^{15}$.

En consecuencia, hay determinados grupos de drogas cuya fracción libre se modificará en uno $u$ otro sentido en el paciente quemado, modificando su efecto clínico y su tasa de eliminación.

Se debe tener en cuenta además, que en la medida que una droga disminuye su unión a proteínas, eleva su volumen de distribución (ej. benzodiacepinas), sin embargo, ya que la mayoría de las drogas anestésicas no poseen una unión a proteínas alta y a que los cambios hemodinámicos que se observan en los pacientes quemados son tan marcados, el efecto producido por la modificación de la concentración plasmática de estas proteínas sobre la acción farmacológica de los anestésicos, en general es mínimo.

\section{Volumen de distribución}

Dos de las alteraciones previamente descritas influyen en producir un aumento del volumen de distribución de algunas drogas: la unión a proteínas y el volumen extracelular.

Como ambos parámetros se encuentran profundamente alterados en los pacientes quemados, drogas con alta unión a proteínas, particularmente a albúmina y cuyos volúmenes de distribución normales se aproximan al volumen extracelular, sufrirán aumentos más importantes del volumen de distribución.

El aumento del volumen de distribución podría disminuir el efecto de una droga, en especial en lo que se refiere a la dosis de carga, pero algunos autores señalan que sólo son requeridos ajustes en la dosis cuando dicha droga posee un volumen de distribución bajo (menor a $30 \mathrm{~L})^{16}$.

Como se verá posteriormente, las drogas de uso anestésico habitual pudieran sufrir algún cambio en su efecto producto de esta condición. 


\section{Clearance}

El clearance de una droga se encuentra influenciado por cuatro factores: metabolismo, excreción renal, unión a proteínas y eventualmente alguna vía de excreción alternativa.

Las drogas que poseen una tasa de eliminación hepática alta, son básicamente dependientes del flujo sanguíneo hepático y bastante independientes de su tasa de unión a proteínas. Por conclusión obvia, el clearance de estas drogas podría elevarse en forma importante durante la fase hiperdinámica descrita en el paciente gran quemado.

Por el contrario, aquellas drogas que poseen una tasa de eliminación hepática baja, presentan un clearance menos sensible a los cambios de flujo hepático pero más sensible a la concentración de proteínas plasmáticas ${ }^{16}$. En este caso, se debe reiterar que la modificación en la tasa de eliminación dependerá de si la droga se une a albúmina o a glicoproteína alfa1-ácida.

Independiente de ello, las drogas de bajo coeficiente de extracción hepática poseen un clearance más sensible a la actividad enzimática del órgano. Al respecto existen estudios en pacientes quemados, que reportan deterioro de las reacciones de fase I (oxidación, reducción e hidroxilación), mientras las reacciones de fase II (conjugación) se encuentran relativamente preservadas $^{17}$. Ejemplo de ello son algunos estudios acerca de la farmacocinética de la morfina, cuya metabolización en fase II (glucoronización), no estaría afectada en estos pacientes, observándose un clearance normal o alto ${ }^{18,19}$.

Los cambios en el flujo sanguíneo renal, dependiendo de la fase del trauma en que se encuentre el paciente, podrían significar cambios importantes en la tasa de excreción renal. Pero estos cambios han sido solo mínimamente demostrados para algunos antibióticos ${ }^{20} \mathrm{y}$ aparentemente no tienen relevancia en el caso de las drogas de uso anestésico habitual.

Del mismo modo, la eliminación farmacológica a través del exudado de la zona quemada ha sido reportada como una vía alternativa de excreción, particularmente en el caso de algunos antibióticos (aminoglucósidos) ${ }^{21}$, pero no existen reportes que validen dicha vía en el caso de otras drogas anestésicas de uso habitual en el paciente quemado.

Finalmente, pese a todas estas consideracio- nes teóricas, la amplia variabilidad entre paciente y paciente que muestran la función renal y hepática en el gran quemado, hacen recomendable realizar una titulación cuidadosa de los efectos de cada droga, para obtener el efecto deseado en cada paciente ${ }^{17}$.

\section{Efectos sobre la técnica anestésica}

Como se señaló previamente, el paciente gran quemado puede recibir cualquier técnica anestésica y esta será efectiva y en general segura, en la medida que se elija adecuadamente de acuerdo a la ubicación y extensión de la injuria, la condición clínica previa y la experiencia del anestesiólogo.

La anestesia general convencional, utilizando una combinación de un opiáceo, un hipnótico, un agente inhalatorio halogenado y un relajante muscular, es la técnica más ampliamente utilizada en la cirugía de escarectomía e injerto dermoepidérmico ${ }^{22}$. La anestesia endovenosa total ha ido aumentando su uso en estos pacientes en la medida que los anestesiólogos se han familiarizado con la técnica y las condiciones hemodinámicas del paciente lo permitan. Con la limitación del uso de succinilcolina como bloqueador neuromuscular, la selección de cualquiera de los otros agentes no constituye un factor crítico que influya en el resultado final.

\section{Anestésicos inhalatorios halogenados}

Dentro de la elección del anestésico inhalatorio, hace un par de décadas la controversia se centraba en el riesgo teórico de hepatotoxicidad inducida por exposiciones repetidas a halotano, sobre todo en pacientes pediátricos inducidos por vía inhalatoria ${ }^{23}$. Sin embargo, en la actualidad, existiendo la alternativa del sevoflurano como agente inductor inhalatorio, dicha controversia ya no existe.

Respecto a los efectos cardiovasculares de los halogenados actualmente en uso, en cualquiera de las etapas hemodinámicas en que se encuentre el paciente, estos no parecen tener importancia en la elección de alguno de ellos por sobre los otros.

\section{Agentes inductores endovenosos}

En relación a los agentes inductores endovenosos, es posible elegir cualquiera de ellos, desde el tiopental o propofol en paciente estables, hasta 
el etomidato en los pacientes inestables desde el punto de vista hemodinámico ${ }^{22}$.

Mención aparte merece la ketamina, droga que en referencias de las décadas del $70 \mathrm{y}$ del 80 era señalada como el agente endovenoso más utilizado ${ }^{24}$. Las ventajas atribuidas a la ketamina son: su estabilidad hemodinámica, sobre todo en pacientes que no presentan depleción de catecolaminas endógenas, su intenso efecto analgésico postoperatorio y la posibilidad de inyección intramuscular en ausencia de un acceso venoso. Estas propiedades, aún válidas 3 décadas después, hacen de esta droga una buena alternativa en el año 2015.

Sin embargo, además de las reacciones diaforéticas que se relacionan con su uso, hoy en día se le reconoce un segundo efecto adverso relacionado con que el período de recuperación es más prolongado cuando se compara con potentes analgésicos de más reciente aparición como el remifentanil ${ }^{25}$. Este punto no es menor, puesto que el estado hipermetabólico descrito en los pacientes quemados, exige que el aporte nutricional sufra las menores interrupciones posibles. Considerando que estos pacientes pueden ser sometidos a procedimientos quirúrgicos y curativos bajo anestesia general o sedación profunda, con mucha frecuencia, las tendencias actuales sugieren ayunos preoperatorios no mayores a $4 \mathrm{~h}$ $\mathrm{y}$ anestesias o sedaciones que permitan una rápida recuperación postoperatoria, para reiniciar la nutrición lo antes posible.

Existen algunas consideraciones de tipo farmacocinético que deben tenerse en cuenta en relación al uso de propofol que eventualmente podrían significar una adaptación de la dosis, tanto en el caso de los bolos de inducción como de las infusiones de mantención.

En la fase hiperdinámica del paciente quemado, existe un aumento del volumen de distribución y del clearance de propofol ${ }^{26,27}$. En paralelo, la disminución de su unión a proteínas plasmáticas significa un aumento de la fracción libre, particularmente en el caso de infusiones prolongadas. Esto pudiera potenciar aún más el aumento del clearance renal y hepático, secundario al aumento del flujo sanguíneo a ambos órganos. Por otro lado, en el caso que el paciente presente daño pulmonar secundario a injuria inhalatoria, esta condición pudiera alterar el flujo sanguíneo pulmonar y reducir la captación y eliminación de la droga que tiene lugar en dicho órgano ${ }^{28}$.

Existen referencias que especulan respecto a un posible efecto farmacodinámico, con aumento de la resistencia del receptor, que contribuiría a una disminución del efecto hipnótico de la dro$\mathrm{ga}^{27,28}$. Exista o no dicho efecto, desde el punto de vista clínico, se debe considerar que pacientes con quemaduras extensas pudieran requerir de bolos e infusiones mayores para obtener y mantener concentraciones plasmáticas y consecuentemente efectos hipnóticos adecuados.

\section{Opioides}

Los opioides son una herramienta fundamental en el manejo del gran quemado, considerando que estos pacientes experimentan intenso dolor de base y en relación a todos los procedimientos quirúrgicos y curativos. Su uso no sólo se circunscribe a la fase aguda de la injuria, sino se prolonga hasta el período de la cirugía reconstructiva.

El amplio espectro de opioides disponibles en la actualidad ofrece alternativas con diferente potencia, duración de acción y efectos colaterales. La reciente adición del remifentanil como un opioide de duración ultracorta, permitió la realización de anestesia principalmente basada en la narcosis, con períodos de recuperación cortos, lo cual ya ha sido señalado como beneficioso por razones nutricionales ${ }^{25}$.

La morfina continúa siendo en la actualidad uno de los opioides más utilizados en el control analgésico del paciente quemado. Los estudios que analizan el comportamiento farmacocinético de la morfina en el paciente quemado son inconsistentes. Mientras algunos estudios refieren disminución en el volumen de distribución y en el clearance, con el consecuente aumento en la vida media de eliminación ${ }^{19}$, otros no encontraron diferencias farmacocinéticas entre pacientes adultos quemados y no quemados ${ }^{18}$.

En el caso del fentanilo, existen reportes que identifican como la principal alteración farmacocinética un aumento de su volumen de distribución ${ }^{29}$.

No obstante, los cambios farmacocinéticos observados no explican en forma exclusiva la resistencia a estas drogas desarrollada entre pacientes quemados, atribuyéndose un rol preponderante a alteraciones farmacodinámicas relacionadas con cambios en el receptor opioide.

En consecuencia y, teniendo en cuenta la gran 
variabilidad en la respuesta a los opioides y la posibilidad siempre latente de rápido desarrollo de resistencia, el concepto clave es que en el paciente quemado se requiere titulación individual de los efectos deseados, control estricto de los efectos colaterales y constante reevaluación de la efectividad de la terapia ${ }^{22}$.

\section{Bloqueadores neuromusculares}

En relación al manejo anestésico del paciente quemado, el efecto más significativo de todos los fármacos utilizados en anestesia es la alteración de la respuesta a los bloqueadores neuromusculares (BNM).

El paciente quemado es susceptible de recibir anestesia general tanto en el momento de la urgencia, durante los primeros días después de una quemadura (curaciones, escarectomías, desbridamientos e injertos dermoepidérmicos), como en forma electiva (cirugía reparadora). Los BNM pueden requerirse como agentes de primera línea durante la reanimación, en el pabellón y en la unidad intensiva, para la adaptación a ventilación mecánica.

La elección del BNM que se debe utilizar en cada momento depende de múltiples factores, pues en el paciente quemado ocurren variados estados fisiopatológicos en diferentes etapas: una primera fase (días) marcada por edema e hipovolemia y una segunda fase (semana a meses) hipercinética, que dura hasta que se complete totalmente la recuperación de la quemadura. Existe también la posibilidad de que ocurran habitualmente durante la evolución del paciente quemado situaciones como: sepsis, fallo multiorgánico, eventualmente insuficiencia renal y/o hepática, así como desnutrición con hipoproteinemia $^{30}$. Todas situaciones que pueden interferir con la farmacocinética y la farmacodinamia de los BNM y decidir la elección de uno de ellos.

Desde el comienzo de su uso en clínica, en términos muy generales, se ha descrito en los pacientes quemados una resistencia a los BNM no despolarizantes ${ }^{31,32}$ y una peligrosa alza de los niveles de potasio después de la administración de succinilcolina ${ }^{33}$. Esta respuesta alterada es proporcional a la superficie quemada y plantea problemas específicos en el paciente quemado, con respuestas diferentes a las de los pacientes sin quemadura.

\section{Resistencia a los BNM no despolarizantes}

La resistencia a los BNM no despolarizantes se ha reportado en todos aquellos utilizados actualmente en clínica, con la única excepción del mivacurio. $\mathrm{La}^{\mathrm{DE}} \mathrm{g}_{95}$ de los $\mathrm{BNM}$ no despolarizantes aumenta 3 a 5 veces y este aumento se correlaciona con el porcentaje de superficie quemada y con el tiempo transcurrido desde que ocurrió la quemadura ${ }^{34}$. De este modo, para conseguir el mismo grado de bloqueo, tanto la dosis que debe ser administrada, como las concentraciones plasmáticas que deben ser alcanzadas deben aumentarse 2 a 3 veces ${ }^{35}$.

La resistencia es de instalación rápida ${ }^{36}$, alcanza un máximo a las 2 semanas, pudiendo llegar a meses en los grandes quemados, y disminuye gradualmente cuando van cicatrizando las heridas; se ha descrito la respuesta alterada hasta después de un año ${ }^{37}$ e incluso 18 meses $^{38}$ y se ha demostrado una respuesta normal después de 3 años para el atracurio y el vecuronio ${ }^{39,40}$.

En quemados con una superficie corporal de hasta un $10 \%$, la resistencia a BNM no despolarizantes es casi inapreciable ${ }^{41}$. A partir del $15 \%$ de superficie quemada se produce un aumento de requerimiento, existiendo una perfecta correlación de la curva dosis-respuesta con la superficie quemada, llegándose a necesitar 2,5 a 5 veces las dosis de un sujeto normal ${ }^{42}$. La imprevisibilidad de la respuesta hace necesario el uso rutinario de monitorización de la función neuromuscular.

La base de esta respuesta alterada son cambios similares a un estado de denervación; una evidencia indirecta de aquello es que al comparar los flujos sanguíneos de una pierna quemada con una no quemada, no hay variaciones debidas al cambio de temperatura ${ }^{43}$. Esto significa que la injuria térmica está asociada a una denervación química o física, que da cuenta de la falta de respuesta vasomotora a la temperatura.

La causa de esta respuesta anormal a los BNM no despolarizantes parece ser multifactorial: cambios en la unión neuromuscular, cambios farmacocinéticos, factores neurohumorales $\mathrm{y}$ aumento de los niveles de catecolaminas.

\section{Cambios en la unión neuromuscular}

La respuesta alterada a los BNM está relacionada tanto a variaciones cualitativas como cuantitativas de los receptores de acetilcolina (AChRs) de la membrana del músculo esquelé- 
tico, que resultan en cambios farmacodinámicos. Se han identificado receptores de acetilcolina en el músculo esquelético, el sistema nervioso central y periférico, y en los ganglios del sistema nervioso autónomo. Se conocen al menos tres tipos de receptores nicotínicos en la unión neuromuscular: los receptores presinápticos que se encuentran en la terminal nerviosa y los receptores postsinápticos en el músculo, que según su ubicación se clasifican en intrasinápticos y extrasinápticos (también conocidos como unionales y extraunionales).

Los AChRs de la unión neuromuscular del músculo normalmente inervado son sólo unionales y están formados por una proteína pentamérica compuesta por cinco subunidades, 2 alfa uno $(\alpha 1), 1$ beta uno $(\beta 1), 1$ épsilon $(\varepsilon)$ y 1 delta $(\delta), y$ son considerados AChRs "maduros" o $\varepsilon A C h R s$ (Figura 1A). Los sitios de unión específicos de los agonistas son las subunidades $\alpha$. Aunque normalmente se sintetiza solo este tipo de receptores, el núcleo de la célula muscular tiene la capacidad de sintetizar otras 2 isoformas de AChRs cuando hay falta de actividad neuronal, como ocurre en el feto antes de completada la inervación, después de una quemadura o de una denervación: los AChRs "inmaduros" y los "neuronales". Los AChRs inmaduros o $\gamma$ AChRs, caracterizados por la sustitución de la subunidad épsilon $(\varepsilon)$ por una gama $(\gamma)$, se desarrollan en la placa neuromuscular, pero también en la membrana muscular a nivel extrasináptico ${ }^{44}$ (Figura 1B). Los $\gamma \mathrm{AChRs,}$ tienen varias diferencias con los normales o "maduros": diferencias en su vida media (menos de $24 \mathrm{~h}$ versus 2 semanas de los $\varepsilon$ AChRs); el tiempo de permeabilidad del canal iónico (2 a 10 veces más tiempo que los $\varepsilon A C h R s)$; diferente sensibilidad a los antagonistas y diferente sensibilidad y/o afinidad de las subunidades $\alpha$ a sus ligandos. Los AChRs neuronales o $\alpha 7$ AchRs están compuestos por 5 subunidades $\alpha 7$ e igualmente se sintetizan durante el desarrollo embrionario y en situaciones de denervación ${ }^{45}$ (Figura 1C). Los $\alpha 7$ AChRs también se diferencian de las otras isoformas: los agonistas endógenos o exógenos tienen la posibilidad de unirse a cada una de las subunidades $\alpha$; concentraciones de colina que no abren los receptores maduros e inmaduros, abren $\operatorname{los} \alpha 7 \mathrm{AChRs}^{46}$.

La acetilcolina, el agonista endógeno, se une a estos receptores; los antagonistas (BNM no

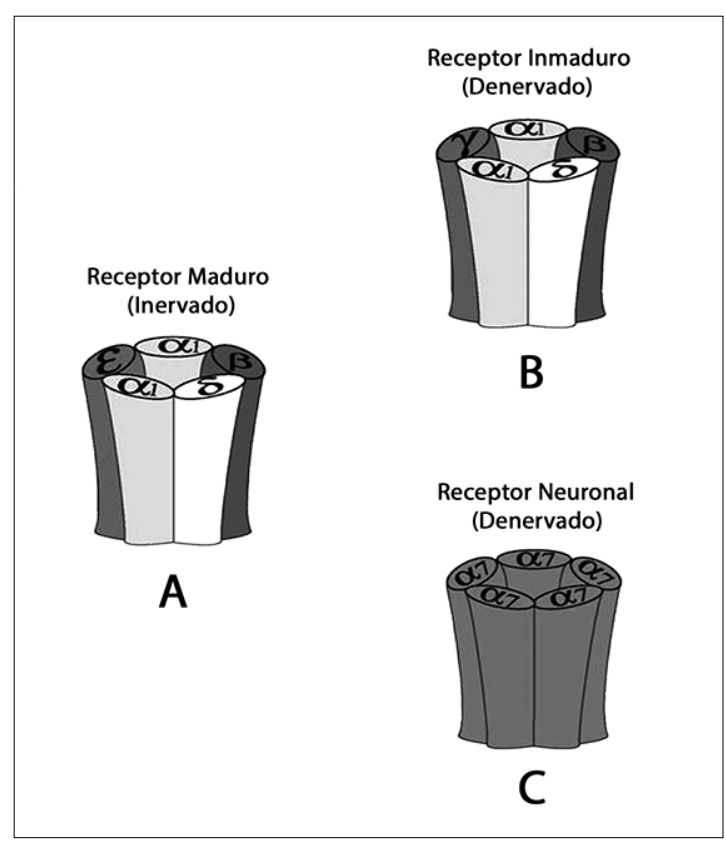

Figura 1. Isoformas de los receptores de acetilcolina susceptibles de ser sintetizados en los núcleos de las células musculares estriadas: A) Receptores maduros o EAChRs;

B) Receptores inmaduros o extrasinápticos o $\gamma \mathrm{AChRs}$ y

C) Receptores neuronales o $\alpha 7 \mathrm{AChRs}$.

despolarizantes, bungarotoxina, etc.), también se unen a ellos pero con diferente afinidad.

Los receptores extrasinápticos y los $\alpha 7 \mathrm{AChRs}$ sufren una involución progresiva luego del nacimiento; desaparecen aproximadamente a los 20 meses, siempre que no haya lesiones nerviosas, falta de movimiento o miopatías que determinen su permanencia por más tiempo. Los receptores extrasinápticos aun cuando no están usualmente presentes en el músculo de adultos normales, son importantes en la medida en que aparecen en los músculos que reciben una estimulación nerviosa menor que la normal.

Estudios en animales de experimentación han demostrado un gran aumento de receptores nicotínicos extrasinápticos incluso en músculos distantes a una superficie quemada ${ }^{47}$. El aumento del número de receptores nicotínicos en la vecindad o a distancia de la quemadura provoca un efecto competitivo con el curare administrado. De este modo, es necesario triplicar la dosis de d-tubocurarina y otros BNM no despolarizantes para bloquear todos los receptores extrasináp- 
ticos inmaduros de un músculo denervado por quemadura u otras causas ${ }^{48}$.

Los receptores extrasinápticos funcionan en la misma forma que los de la unión neuromuscular, interactuando con la acetilcolina y dando origen a una despolarización si el receptor no está bloqueado, pero permanecen abiertos un tiempo mayor y de este modo generando estos canales una corriente más débil ${ }^{49}$.

Mediante estudios realizados sobre el ARN mensajero de las diferentes subunidades de los receptores extrasinápticos en un músculo denervado y en una quemadura, se ha demostrado que el aumento del número de receptores inmaduros que ocurre después de una quemadura no tiene relación con el fenómeno de denervación ${ }^{50,51}$. Otra diferencia de la quemadura es que tampoco aumentan las proteínas miogénicas reguladoras (mio-D y miogenina), como ocurre en el caso de la denervación y la inmovilización prolongada ${ }^{52}$.

Se ha demostrado un aumento de los niveles de AMP cíclico en relación con la superficie quemada y la localización de la quemadura, por lo que el mecanismo del aumento de receptores estaría más bien relacionado con un aumento del ensamblaje y/o la expresión superficial del receptor $^{52}$.

\section{Cambios farmacocinéticos}

Existen modificaciones farmacocinéticas y farmacodinámicas, debidas en parte a alteraciones de la función renal y hepática, a alteraciones hemodinámicas y a disminución de flujos regionales, que también pueden contribuir a la variación de la respuesta a los BNM. Por ejemplo, es bien sabido que varios agentes, incluyendo los BNM, tienen una cinética de eliminación acelerada después de la injuria térmica ${ }^{53}$.

El efecto dilucional de un gran aumento de volumen de distribución y el aumento del clearance pueden explicar parcialmente el aumento de las dosis de BNM no despolarizantes en pacientes quemados. Estas alteraciones farmacocinéticas se correlacionan con el porcentaje de superficie quemada ${ }^{54}$.

Los quemados cursan con hipoproteinemia a partir de la primera semana, fundamentalmente a expensas de la albúmina, que disminuye significativamente por lo menos durante los 7 primeros días; las globulinas por el contrario aumentan. La concentración de alfa glicoproteína ácida aumenta, disminuyendo la relación albúmina/ globulinas. Esta alteración podría explicar el aumento de la unión a proteínas, especialmente por el aumento de la 1-ácido glicoproteína (una alfa globulina $)^{55}$ que se une a los agentes catiónicos, disminuyendo así la fracción libre de los BNM no despolarizantes en el plasma, que es la que puede difundir al sitio efecto ${ }^{56,57}$.

Pero esto no es lo único que contribuye a la resistencia de los pacientes quemados a los BNM no despolarizantes, que como ya se dijo es multifactorial. Por ejemplo, tan sólo un 10\% del pancuronio tiene unión a proteínas plasmáticas, por lo que no puede ser responsable de la resistencia a este fármaco ${ }^{58}$.

\section{Factores neurohumorales}

Al medir la respuesta de la d-tubocurarina y el pancuronio en una preparación de nervio-músculo perfundida con plasma de pacientes quemados y no quemados, se demostró un antagonismo significativo en el caso tratado respecto del grupo control $^{59}$. Parece existir entonces en los pacientes quemados una "sustancia anti-curare" que competiría con los BNM no despolarizantes interfiriendo en su acción. Su efecto se ha demostrado in vitro, pero con una intensidad mucho más débil que lo encontrado in vivo, por el carácter multifactorial que causa la resistencia a los BNM no despolarizantes. Esta sustancia o grupo de sustancias presentes o ausentes en el plasma de los pacientes quemados se une o inactiva a los BNM no despolarizantes y actuaría más sobre la unión neuromuscular que sobre el miocito.

Se ha descrito también otros mediadores que influyen en la resistencia a los BNM no despolarizantes: catecolaminas, prostaglandinas y enzimas hidrolíticas ${ }^{60}$. Por otra parte, la inmovilización producto del reposo en cama o las contracturas que ocurren después de las quemaduras, también pueden contribuir con los mecanismos neurohumorales relacionados con la resistencia a los BNM no despolarizantes ${ }^{45}$.

\section{Aumento de los niveles de catecolaminas}

Se ha atribuido al aumento de los niveles de catecolamina circulante, tanto endógenas como por administración exógena, hecho que ocurre habitualmente en la evolución de los pacientes quemados, como otra posible causa de la resistencia a los BNM no despolarizantes ${ }^{61}$. Las cate- 
colaminas aumentan la actividad del AMP cíclico, que como se ha demostrado, está asociado a la resistencia a los BNM no despolarizantes ${ }^{45}$.

\section{BNM no despolalizantes}

\section{Pancuronio}

El pancuronio no se comercializa actualmente en Chile, pero está disponible en otros países de Latinoamérica. La resistencia al pancuronio es similar a la que ocurre con otros BNM no despolarizantes, especialmente en pacientes con superficie quemada sobre el $25-30 \%$. Debe considerarse la posibilidad de aumentar substancialmente las dosis para obtener el mismo nivel de bloqueo o la misma duración clínica.

Cuando no había otras alternativas se demostró un efecto sinérgico del pancuronio con la metocurina, que era beneficioso en los pacientes quemados, logrando $1 \mathrm{DE}_{95}$ de ambas drogas disminuir el tiempo de inicio de acción (1,3 min), pero aumentar el tiempo de recuperación al $25 \%$ $(2 \mathrm{~h})^{61}$.

En niños la $\mathrm{DE}_{50} \mathrm{y} \mathrm{DE}_{95}$ de los pacientes sanos es de 0,03 y $0,05 \mathrm{mg} \cdot \mathrm{kg}^{-1}$ respectivamente y en niños quemados 0,08 y $0,5 \mathrm{mg} \cdot \mathrm{kg}^{-1}$; la $\mathrm{DE}_{95}$ puede llegar a $0,14 \mathrm{mg} \cdot \mathrm{kg}^{-1}$ si la superficie quemada es mayor de $65 \%{ }^{62}$. Esto significa que se necesita 3 a 10 veces la dosis de pancuronio para producir el mismo efecto.

\section{Atracurio}

La resistencia al atracurio comienza alrededor del sexto día después de la quemadura, alcanza su intensidad máxima entre los 15 y 40 días y comienza a normalizarse a los 70 días, pero puede estar presente hasta 700 días después de la quemadura ${ }^{63}$.

Durante el período de resistencia, la dosis habitual de intubación de $0,5 \mathrm{mg} \cdot \mathrm{kg}^{-1}$ de atracurio produce sólo una depresión máxima del $73 \%$ de bloqueo a los 7,3 min en pacientes con más de $33 \%$ de superficie quemada, y una depresión máxima de sólo $61 \%$ a los $8,5 \mathrm{~min}$ en aquellos con más del $66 \%$ de superficie quema$\mathrm{da}^{35}$. No se ha logrado conseguir bloqueo completo en pacientes quemados con dosis de hasta $0,75 \mathrm{mg} \cdot \mathrm{kg}^{-1}{ }^{64}$. Si se intenta aumentar la dosis para lograr mejores condiciones de intubación, la liberación de histamina que producen las altas dosis puede producir hipotensión arterial.
La duración de una dosis de $0,5 \mathrm{mg} \cdot \mathrm{kg}^{-1} \mathrm{de}$ atracurio hasta alcanzar el 50\% de recuperación, que es de alrededor de 45 min en pacientes sanos, se acorta a 25 en los pacientes quemados con una superficie de 33\%-66\%.

$\mathrm{La} \mathrm{DE}_{95}$ del atracurio no se modifica hasta un $20 \%$ de la superficie quemada, pero se duplica en los pacientes con superficie quemada entre $20 \%$ y $60 \%$ y se multiplica por 10 en aquellos con una superficie quemada mayor al $60 \%{ }^{65}$.

A pesar de la posibilidad de liberación de histamina, el atracurio puede tener indicación en los pacientes con insuficiencia renal y/o hepática, pero especialmente el cisatracurio, un isómero del atracurio que no libera histamina en dosis clínicas, pudiendo aumentarse sin temor las dosis para lograr buenas condiciones de intubación. El atracurio y cisatracurio son independientes de los órganos para su eliminación, debido a distintos grados de participación de hidrólisis plasmática y de la eliminación de Hofmann en su metabolización.

\section{Vecuronio}

$\mathrm{La} \mathrm{DE}_{95}$ del vecuronio también aumenta proporcionalmente a la superficie de la quemadura. $\mathrm{La} \mathrm{DE}_{95}$ de un paciente sano es de $35,3 \mu \mathrm{g} \cdot \mathrm{kg}^{-1}$; aumenta a $68,2,111,1$ y $129,4 \mu \mathrm{g} \cdot \mathrm{kg}^{-1}$ con superficies quemadas de hasta $40 \%$, entre $40 \%-60 \%$ y más de $60 \%$ respectivamente ${ }^{41}$.

Se ha medido el aumento de resistencia al vecuronio en niños quemados de hasta 17 años; la curva dosis-respuesta tiene un cambio similar, desplazándose a la derecha (mayor requerimiento de dosis) en forma proporcional a la superficie quemada ${ }^{40}$.

Hay estudios que demuestran el acortamiento del tiempo de inicio de acción del vecuronio hasta 1 min usando hasta $6 \mathrm{DE}_{95}$, en la medida que no produce alteraciones hemodinámicas y pudiera reemplazar a la succinilcolina, a cambio de una recuperación más lenta. Todos ellos perdieron su validez tras la aparición del rocuronio ${ }^{66}$.

La farmacocinética del vecuronio contribuye con el aumento de su resistencia, aunque forma parte de una combinación de varios factores. Los pacientes quemados presentan un clearance de distribución $\left(\mathrm{CL}_{3}\right)$ facilitado en la fase terminal $\left(0,12\right.$ versus $\left.0,095 \mathrm{~L} \cdot \mathrm{min}^{-1}\right)$, lo que se traduce en una vida media de eliminación más corta $(5,5$ versus $6,6 \mathrm{~h})^{67}$. En resumen, el análisis farmaco- 
cinético sugiere que el grado y extensión de la distribución tisular de vecuronio está aumentado en los pacientes quemados, dando como resultado una rápida disminución de sus concentraciones plasmáticas en las fases de distribución y terminales. Esta distribución alterada de la droga en los tejidos puede explicar en parte la resistencia a este BNM en los pacientes con quemaduras graves.

\section{Mivacurio}

Al contrario de lo que ocurre con los otros BNM no despolarizantes, los estudios farmacodinámicos sugieren un aumento de la sensibilidad al mivacurio. Puesto que el mivacurio es metabolizado por la seudocolinesterasa plasmática, que está disminuida en los pacientes quemados ${ }^{68}$, esta respuesta diferente puede explicarse por una predominancia del efecto de la disminución de la actividad de la seudocolinesterasa (que causa sensibilidad), por sobre los cambios cualitativos y cuantitativos en la expresión de los receptores de acetilcolina (que causan resistencia). Se ha demostrado una significativa correlación entre la disminución de los niveles de colinesterasa plasmática y el tiempo de recuperación ${ }^{69}$.

En un estudio realizado en adultos, se demostró un acortamiento del tiempo de inicio de acción en pacientes quemados después de una dosis de $0,15 \mathrm{mg} \cdot \mathrm{kg}^{-1}$ de mivacurio de 3 a 1,3 min y el aumento del tiempo de duración clínica de 15,3 a $24,6 \mathrm{~min}^{70}$. Otro estudio más reciente en adultos con $0,2 \mathrm{mg} \cdot \mathrm{kg}^{-1}$ demostró un pequeño aumento del tiempo de inicio de acción (115 versus 90 segundos) y un significativo aumento de la duración clínica (36 versus $22 \mathrm{~min})^{71}$.

Dos estudios realizados en niños de 2 a 12 $\operatorname{años}^{72}$ y en adolescentes de 13 a 18 años ${ }^{73}$ demuestran el mismo aumento de la duración de acción, pero sin diferencia significativa en el tiempo de inicio, que se mantiene en 2 a 3 min, aunque llega a 2 min en pacientes con mayor superficie quemada. De este modo, una dosis habitual de intubación de $0,2 \mathrm{mg} \cdot \mathrm{kg}^{-1}$ produce buenas condiciones de intubación en un tiempo similar a los pacientes no quemados (2-3 min), con tiempos de duración clínica prolongados un 30\% (20 min). En ambos la respuesta diferente es proporcional a la superficie quemada (se expresa significativamente con un $30 \%$ ) y con la actividad de la seudocolinesterasa (también con un máximo de disminución con el $30 \%$ de superficie quemada).

De este modo, el mivacurio en dosis normales es una alternativa eficaz y razonable a otros BNM no despolarizantes, teniendo en cuenta que una pequeña liberación de histamina puede contraindicarlo en pacientes hemodinámicamente inestables.

\section{Rocuronio}

El rocuronio, por su corto tiempo de inicio de acción, ha sido la alternativa natural de reemplazo de la succinilcolina en la inducción en secuencia rápida. En adultos con una superficie quemada mayor a $25 \%$ sin embargo, el tiempo de inicio de acción aumenta: con dosis de $0,9 \mathrm{mg} \cdot \mathrm{kg}^{-1}$ (3 $\mathrm{DE}_{95}$ ) se logra en 115 segundos y con $1,2 \mathrm{mg} \cdot \mathrm{kg}^{-1}$ $\left(4 \mathrm{DE}_{95}\right.$ ) en 86 segundos versus 58 y 57 segundos respetivamente en pacientes no quemados ${ }^{74}$.

A pesar de todo, 86 segundos pudiera ser aún demasiado tiempo para una intubación en secuencia rápida en pacientes con compromiso de la función respiratoria ${ }^{75}$. Además, los tiempos de inicio siguen disminuyendo al subir la dosis de 3 a $4 \mathrm{DE}_{95}$ en los pacientes quemados, pero llegan a un efecto techo de 58-56 segundos en el grupo control; de hecho, en otro estudio, con 0,5 $\mathrm{mg} \cdot \mathrm{kg}^{-1}$ se logran tiempos de inicio de 30 segun$\operatorname{dos}^{76}$.

Los tiempos de recuperación son todos significativamente más cortos después de una quemadura comparado con la misma dosis en grupo control: la duración de acción clínica (al 25\% de recuperación) disminuye de 89,4 a 69,1 min con $3 \mathrm{DE}_{95}$ de rocuronio y de 115,1 a 90,8 min después de $4 \mathrm{DE}_{95}$; la recuperación a un tren de 4 estímulos de 0,8 disminuye de 132,4 a 102,9 $\mathrm{min}$ con $3 \mathrm{DE}_{95} \mathrm{y}$ de 162,4 a 125,5 min con $4 \mathrm{DE}_{95}$. El aumento de la dosis de 0,9 a $1,2 \mathrm{mg} \cdot \mathrm{kg}^{-1}$ aumenta la duración de todas las variables de recuperación tanto en los pacientes quemados como en el grupo control ${ }^{75}$.

\section{Hiperkalemia tras la administración de BNM despolarizantes}

Desde hace más de 40 años se ha descrito el riesgo de hiperkalemia y eventualmente paro cardiaco tras la administración de succinilcolina en el paciente quemado ${ }^{77-79}$. Hay una gran dispersión entre las diferentes publicaciones en cuanto 
al momento en que aparece este riesgo aumentado, desde las primeras $24 \mathrm{~h}$ hasta siete días después de ocurrida la quemadura ${ }^{80-82}$.

También influye la superficie corporal quemada con la exagerada liberación de potasio. Esta parece comenzar sólo cuando la superficie es mayor del $15 \%^{41}$ y especialmente cuando hay musculatura implicada en la quemadura ${ }^{83}$, aunque está descrita en pacientes con superficies quemadas incluso menores de un $10 \%{ }^{45}$.

En la musculatura esquelética normal, el proceso de polarización y despolarización producido por la administración de succinilcolina aumenta la kalemia $0,5 \mathrm{mmol} \cdot \mathrm{L}^{-1} 84$. En pacientes quemados, dosis de $0,4 \mathrm{mg} \cdot \mathrm{kg}^{-1}$ de succinilcolina producen un aumento de hasta $6 \mathrm{mmol} \cdot \mathrm{L}^{-145}$.

Los niveles de potasio aumentan después de los primeros minutos de la administración endovenosa de succinilcolina, alcanzando niveles máximos entre los 2-5 min, disminuyendo progresivamente hasta los $15 \mathrm{~min}^{33}$. Esta masiva hiperkalemia puede conducir a taquicardia ventricular y/o fibrilación ventricular con paro cardiaco, lo que está favorecido por la inestabilidad hemodinámica, la acidosis y la hipercapnia. La respuesta hipekalémica es imprevisible e independiente de los niveles de potasio en el momento de administración de la succinilcolina. La duración de esta respuesta alterada es variable, pero se ha descrito hasta 2 años después de una injuria térmica mayor ${ }^{41}$.

Ante la aparición de cambios electrocardiográficos compatibles con hiperkalemia ( $\mathrm{T}$ picudas, $\mathrm{p}$ angostas o ausentes, complejos QRS anchos, etc.), que no siempre aparecen, el objetivo del tratamiento debe ser antagonizar el efecto de los altos niveles de potasio sobre la conducción AV y desplazar el potasio del extra al intracelular. Se recomienda 1 ó 2 ampollas de $10 \mathrm{ml}$ de cloruro o gluconato de calcio administradas en 2-3 $\mathrm{min}\left(0,5 \mathrm{~mL} \cdot \mathrm{kg}^{-1}\right.$ en niños). Otros agentes que facilitan la entrada de potasio a la célula son la insulina con glucosa, las catecolaminas y el bicarbonato de sodio. Cuando sea necesario debe iniciarse la resucitación cardiopulmonar.

Además de la respuesta hiperkalémica, los pacientes quemados presentan una hipersensibilidad al efecto BNM de la succinilcolina: se necesitan dosis menores que en los pacientes no quemados para producir el mismo grado de bloqueo. Una dosis de $0,1-0,2 \mathrm{mg} \cdot \mathrm{kg}^{-1}$ produce un bloqueo máximo mayor al $80 \%$, sin modificar los niveles de potasio ${ }^{85}$.

Igual que en el caso de la respuesta alterada a los BNM no despolarizantes, se ha planteado que la respuesta alterada a la succinilcolina en el paciente quemado es multifactorial, pero fundamentalmente relacionada con el aumento del número y el tipo de receptores nicotínicos de la unión neuromuscular y la sobrerregulación de estos. El aumento de receptores inmaduros y $\alpha 7 \mathrm{AChRs}$, así como una apertura más prolongada de los canales iónicos, contribuiría al efecto hiperkalémico exagerado ${ }^{45,86}$. La proporción en que están presentes cada uno de estos subtipos se desconoce, pero el número total de AChRs aumenta enormemente en relación a un músculo inervado.

También la teoría relacionada con la interacción de antagonistas o agonistas con receptores sobrerregulados (aumentados) o subrregulados (disminuidos) se usa para explicar el aumento de la sensibilidad de los BNM despolarizantes (succinilcolina). Los términos sobre o subrregulación se refieren a cambios en la disponibilidad del número total de receptores, pero que no implican un cambio de las isoformas, que pueden afectar tanto a los BNM no despolarizantes como a la succinilcolina. La succinilcolina se comporta como agonista porque al estar compuesta por 2 moléculas de acetilcolina unidas, inicialmente estimula al receptor antes de causar parálisis. Cuando hay un aumento de receptores hay entonces tanto un aumento a la sensibilidad de los agonistas como una disminución de la sensibilidad a los antagonistas. El extremado aumento de sensibilidad a los agonistas produce como resultado una respuesta hiperkalémica letal a la succinilcolina, sobre todo porque, a diferencia de la acetilcolina es metabolizada más lentamente, manteniendo la despolarización y exagerando la liberación de potasio. Además, los receptores inmaduros pueden ser despolarizados con concentraciones de succinilcolina más bajas ${ }^{87}$, persistiendo la despolarización, sumado a que el producto de metabolización de la succinilcolina, la colina, es un potente agonista de los $\alpha 7 \mathrm{AChRs}^{46}$.

Dependiendo en parte de la magnitud de la superficie quemada, los pacientes quemados tienen una disminución de la actividad de la seudocolinesterasa plasmática, por lo que la succinilcolina se metaboliza menos y llega en mayor 
concentración a la unión neuromuscular ${ }^{45}$, bajando sus requerimientos. Dosis de sólo 0,1 a 0,2 $\mathrm{mg} \cdot \mathrm{kg}^{-1}$ en caso necesario, sólo para el manejo de una vía aérea difícil, son suficientes para lograr una relajación que permite buenas condiciones de intubación ${ }^{86}$.

\section{Elección de los BNM según situaciones clínicas}

\section{Reanimación del gran quemado}

En la reanimación del gran quemado, por las condiciones hemodinámicas y muchas veces por la quemadura de la vía aérea subyacente, la intubación endotraqueal es habitualmente necesaria, muchas veces en condiciones de estómago lleno. Esto puede ser realizado tanto en el box de urgencia como en la atención prehospitalaria si fuera necesario.

Las intervenciones más frecuentes en el período agudo son: aseo quirúrgico inicial, escarotomía, fasciotomía, descompresión de tronco; la balneoterapia es un procedimiento que se ha abandonado en muchos centros, pero que se realiza bajo anestesia general al ingreso del paciente, para su evaluación y tratamiento. A veces puede esperarse el ayuno para realizar anestesia general, pero hay situaciones urgentes en las que hay que correr el riesgo de aspiración de contenido gástrico, utilizando las técnicas habituales de intubación en secuencia rápida.

Una alternativa para evitar el uso de BNM es la intubación con el paciente despierto o con una moderada sedación y anestesia tópica para minimizar el riego de aspiración broncopulmonar. Esta debe ser una técnica protocolizada y realizada por anestesiólogos que tengan experiencia; no siempre el gran quemado es un buen candidato, por sus condiciones hemodinámicas y poca colaboración.

Existe controversia en relación al uso de succinilcolina en la reanimación del gran quemado. Desde el punto de vista de la evidencia actual, hay pocos datos clínicos que demuestren un alza desproporcionada de potasio antes de las 2 semanas porque siempre ha tratado de evitarse su uso. Varios autores recomiendan su suspensión entre las $24 \mathrm{~h}$ a 21 días $^{38,88}$. A partir de evidencia indirecta experimental, J.A. Jeevendra Martyn, quien más ha publicado sobre el tema, recomienda contraindicar la succinilcolina desde los 2 días después de la quemadura ${ }^{47,82}$, lo que parece más prudente. Sin embargo, lo más racional es evitar completamente su uso en todas las etapas del paciente quemado y durante los dos años posteriores a la quemadura, con la excepción de situaciones de riesgo de vida (laringoespasmo, manejo de vía aérea difícil) en que se recomienda usar dosis 5-10 veces menores a las habituales. Se ha demostrado que con sólo $0,2 \mathrm{mg} \cdot \mathrm{kg}^{-1}$ de succinilcolina se obtiene un $90 \%$ de bloqueo en niños, sin el desarrollo de una hiperkalemia peligrosa ${ }^{86}$.

Después de la aparición del rocuronio, la tendencia es a su abandono, debido no sólo a la hiperkalemia sino a la gran cantidad de complicaciones asociadas a su uso, aunque la resistencia de los pacientes quemados a los BNM no despolarizantes puede tener implicancias clínicas significativas.

Con el uso de rocuronio en dosis habituales de intubación $\left(0,6 \mathrm{mg} \cdot \mathrm{kg}^{-1}\right)$, puede lograrse condiciones de intubación satisfactorias con 30 segundos de diferencia a favor de la succinilcolina; con dosis mayores $\left(1,5 \mathrm{mg} \cdot \mathrm{kg}^{-1}\right)$, se ha logrado en pacientes quemados tiempos de inicio de acción de 30 segundos, similares a los logrados con el uso de priming con solo $1 \mathrm{mg} \cdot \mathrm{kg}^{-1}$, pero $\sin$ los posibles inconvenientes de este procedimiento ${ }^{77}$. El priming, sin embargo, no atenúa la liberación de potasio de la succinilcolina, pues la cantidad de cualquier BNM no despolarizante es mucho mayor para bloquear los $\alpha 7 \mathrm{AChRs}$ que los receptores normales ${ }^{88}$.

Para la inducción en secuencia rápida de un paciente quemado el rocuronio es el agente de elección. Se recomienda una dosis de 1,2 $\mathrm{mg} \cdot \mathrm{kg}^{-1}$; aunque su duración de acción puede tener una mayor variabilidad y alargarse demasiado, con el uso de una adecuada monitorización, se puede lograr una adecuada reversión en caso necesario, especialmente después de la incorporación del sugammadex.

Si no hay estómago lleno, cualquier BNM no despolarizante puede usarse en la intubación endotraqueal de la reanimación del gran quemado, teniendo presente otros aspectos en la elección.

\section{Procedimientos quirúrgicos electivos}

Los BNM forman parte del arsenal farmacológico habitual de la anestesia general inhalatoria o endovenosa total en estos procedimientos: escarectomías tangenciales o "a fascia", con cober- 
turas transitorias o permanentes, aseos quirúrgicos, amputaciones, etc.

Una vez aislada la vía aérea, con las precauciones mencionadas en el estómago lleno y destacando la resistencia de los pacientes quemados a los BNM, el requerimiento de relajación muscular en los procedimientos de aseo quirúrgico, escarectomía e injerto es bajo.

En general es suficiente mantener al paciente en plano quirúrgico con ventilación asistida. Los pacientes con quemadura de la vía aérea, que tienen distress respiratorio e insuficiencia respiratoria, o que tienen lesiones quirúrgicas asociadas, deben ser mantenidos en ventilación mecánica y pueden ser conservados con un bloqueo más profundo.

En aquellos pacientes en que se usó rocuronio al intubar, en general basta la dosis única. En aquellos pacientes que tienen compromiso renal el atracurio y especialmente el cisatracurio, que no produce liberación de histamina en caso de inestabilidad hemodinámica, son los agentes de elección. Las dosis de repetición de los BNM de duración intermedia, cuando son necesarias, deben ser por lo menos un tercio de las dosis de intubación para lograr períodos de relajación de $15 \mathrm{~min}$.

La disminución de la colinesterasa plasmática que ocurre en la evolución de los pacientes quemados convierte al mivacurio en una excepción interesante que no presenta aquella resistencia descrita para los otros BNM no despolarizantes y se transforma en este grupo de pacientes en un BNM de duración intermedia ${ }^{89}$.

La monitorización de la función neuromuscular debe ser rutinaria en estos pacientes; aunque no siempre se cuente con el sitio habitual para una monitorización objetiva (nervio cubital), pues los pacientes quemados frecuentemente tienen comprometidas las manos y los miembros inferiores, debiendo tenerse presente los sitios alternativos (rama oftálmica del quinto par y tibial posterior). La reversión farmacológica del bloqueo neuromuscular debe realizarse con los mismos parámetros del paciente no quemado y las dosis de anticolinesterásicos son las habituales.

\section{BNM en el quemado crítico bajo ventilación mecánica}

Frecuentemente los pacientes quemados necesitan ser ventilados en algún momento de la evolución de la lesión, ya sea por el tipo y extensión de la quemadura, por inestabilidad hemodinámica o el desarrollo de insuficiencia respiratoria (lesión inhalatoria, distress séptico) o la coexistencia de politraumatismo.

A comienzos de los noventa se realizaron serios estudios prospectivos que sugerían que hasta el $70 \%$ de los pacientes críticos podían tener debilidad muscular después de una prolongada administración de vecuronio y pancuronio, lo que hizo finalmente limitar sus indicaciones y disminuir al mínimo indispensable los períodos y la profundidad del bloqueo ${ }^{90,91}$. Objetivamente, la frecuencia de uso de BNM en pacientes críticos ha disminuido en las últimas décadas ${ }^{92,93}$.

Además de las complicaciones inmediatas específicas de cada BNM (liberación de histamina, efecto vagolítico, etc.), los pacientes críticos que reciben BNM están expuestos a otro tipo de complicaciones a más largo plazo: la parálisis con inadecuada analgesia o sedación, los efectos derivados de la acumulación de BNM o alguno de sus metabolitos (3-desacetil metabolitos y laudanosino) y la parálisis prolongada por miopatía o neuropatía ${ }^{94}$.

Algunos pacientes que reciben bloqueadores neuromusculares en forma continua por más de 2 días para facilitar la ventilación mecánica permanecen con debilidad muscular por largo tiempo después de suspender el bloqueo. En términos generales, este bloqueo prolongado es de 2 causas: una prolongación del bloqueo de relativamente corta duración de base farmacocinética, y un bloqueo más persistente, con debilidad y atrofia muscular de base neuromuscular. Este último grupo ha dado origen a una serie de síndromes.

Los factores de riesgo de un bloqueo prolongado son: el uso de vecuronio en pacientes de sexo femenino con insuficiencia renal, el uso concomitante de altas dosis de corticoesteroides, el uso de altas dosis de BNMND por períodos prolongados, la acidosis metabólica, la hipermagnesemia y el desarrollo de taquifilaxia (aumento de la tolerancia) $)^{95,96}$.

Es interesante que en pacientes críticos no quemados se ha asociado también las grandes dosis de BNM durante tiempo prolongado a la sensibilización de los receptores de acetilcolina, al igual que en el paciente quemado ${ }^{97,98}$. Aunque no hay publicaciones que describan este tipo de 
lesiones en pacientes quemados, podrían estar especialmente expuestos a este tipo de complicaciones por lo que parece lógico limitar el uso de BNM mediante el uso racional de analgesia y sedación con opioides y benzodiacepinas. Lo recomendable es usar este recurso sólo ocasionalmente para "adaptar" al paciente al ventilador cuando la sedación es insuficiente.

Cuando se requiere relajación muscular, se recomienda mantener a los pacientes con una respuesta al TOF durante la ventilación mecáni$\mathrm{ca}^{99}$, sin embargo, muchos modelos de ventilación pueden ser efectuados sólo con la supresión de las dos últimas respuestas al TOF ${ }^{100}$. Varios reportes han comunicado la mala experiencia que puede constituir estar con la musculatura paralizada y consciente ${ }^{101}$; es así que los BNM nunca deben ser usados solos en este contexto, sino que siempre asociados a sedantes y narcóticos.

El cisatracurio es el BNM no despolarizante de elección en los pacientes críticos: a diferencia del atracurio, no libera histamina y no produce concentraciones potencialmente peligrosas del metabolito laudanosino. Después de $38 \mathrm{~h}$ de infusión en pacientes críticos, el perfil farmacocinético del cisatracurio es similar que después de una administración en bolo ${ }^{102}$. Se recomienda una dosis de carga de $0,1 \mathrm{mg} \cdot \mathrm{kg}^{-1}$ en bolo, y cuando aparece el primer TOF, se comienza la infusión a una dosis de $2-4 \mu \mathrm{g} \cdot \mathrm{kg}^{-1} \cdot \mathrm{min}^{-1}$. Luego la velocidad de infusión se ajusta de acuerdo a la monitorización del $\mathrm{TOF}^{103}$.

Actualmente existen guías clínicas para el uso de BNM por tiempo prolongado en pacientes críticos $^{104}$. Para prevenir el desarrollo de debilidad muscular, las administraciones por períodos prolongados deben hacerse teniendo en cuenta las siguientes recomendaciones:

- Limitar las indicaciones a los casos justificadamente necesarios.

- Realizar una sedación y analgesia adecuada siempre que se usen BNM.

- Disminuir los tiempos de administración y, en lo posible, no usar BNM por más de $48 \mathrm{~h}$.

- Monitorizar el bloqueo con TOF estimulando el nervio orbicular del ojo (orbicularis oculi), ubicando los electrodos uno por encima y otro por debajo del canto del ojo: la respuesta a observar es el cierre de los párpados.

- Disminuir las dosis manteniendo niveles medianos de relajación, con 2 de 4 respuestas al TOF.

- Realizar discontinuaciones periódicas de los BNM, permitiendo por lo menos una vez al día una recuperación espontánea.

- No administrar concomitantemente corticoesteroides. Si es imprescindible hacerlo, se recomienda el monitoreo diario de las concentraciones de CPK y si aumenta, debe suspenderse la administración de BNM.

- Por su metabolismo independiente de los órganos, ausencia de efectos hemodinámicos $\mathrm{y}$ mínima producción de laudanosino, el cisatracurio es el BNMND que se acerca más al ideal para ser usado en el paciente crítico por largos períodos.

\section{Referencias}

1. Deitch EA. The management of burns. N Engl J Med 1990 Nov;323(18):1249-1253.

2. Horton JW, Baxter CR, White DJ. Differences in cardiac responses to resuscitation from burn shock. Surg Gynecol Obstet 1989 Mar;168(3):201-213.

3. Aikawa N, Martyn JA, Burke JF. Pulmonary artery catheterization and thermodilution cardiac output determination in critical burn management. Am J Surg
1978;135:811-817.

4. Kinsky MP, Guha SC, Button BM, Kramer GC. The role of interstitial starling forces in the pathogenesis of burn edema. J Burn Care Rehabil 1998 JanFeb;19(1 Pt 1):1-9.

5. Baxter CR, Cook WA, Shires GT. Serum myocardial depressant factor of burn shock. Surg Forum 1966;17:1-2.

6. Maass DL, White J, Horton JW. IL-1beta and IL-6 act synergistically with TNF-alpha to alter cardiac contractile function after burn trauma. Shock 2002

Oct;18(4):360-366.

7. Müller-Werdan U, Engelmann

$\mathrm{H}$, Werdan K. Cardiodepression by tumor necrosis factor-alpha.

Eur Cytokine Netw 1998

Dec;9(4):689-691.

8. Kinsky JM, Woodson L, Sherwood E et al. Cardiac dysfunction following large burn injury in children is associated with increased length of icu stay. ESICM 2009; 193: 0006-00228.

9. Davies DM, Pusey CD, Rainford DJ et al. Acute renal failure in 
burns. Scand J Plast Reconstr Surg 1979;13(1):189 192.

10. Cameron JS. Disturbances of renal function in burnt patients. Proc R Soc Med 1969 Jan;62(1):49-50.

11. Jeschke MG, Barrow RE, Wolf SE et al. Mortality in burned children with acute renal failure. Arch Surg 1998 Jul;133(7):752756.

12. Holm C, Hörbrand F, von Donnersmarck GH et al. Acute renal failure in severely burned patients. Burns 1999 Mar;25(2):171-178.

13. Jeschke MG, Mlcak RP, Finnerty $\mathrm{CC}$ et al. Burn size determines the inflammatory and hypermetabolic response. Crit Care 2007;11(4):R90.

14. Williams FN, Herndon DN, Jeschke MG. The hypermetabolic response to burn injury and interventions to modify this response. Clin Plast Surg 2009 Oct;36(4):583-596.

15. Martyn JA, Abernethy DR, Greenblatt DJ. Plasma protein binding of drugs after severe burn injury. Clin Pharmacol Ther 1984 Apr;35(4):535-539.

16. Jaehde U, Sörgel F. Clinical pharmacokinetics in patients with burns. Clin Pharmacokinet 1995 Jul;29(1):15-28.

17. Bonate PL. Pathophysiology and pharmacokinetics following burn injury. Clin Pharmacokinet 1990 Feb;18(2):118-130.

18. Perry SI, Inturrisi CE. Analgesia and morphine disposition in burn patients. J Burn Care Rehabil 1983;4(4):276-279.

19. Furman WR, Munster AM, Cone EJ. Morphine pharmacokinetics during anesthesia and surgery in patients with burns. J Burn Care Rehabil 1990 SepOct;11(5):391-394.

20. Loirat P, Rohan J, Baillet A et al.
Increased glomerular filtration rate in patients with major burns and its effect on the pharmacokinetics of tobramycin. N Engl J Med 1978 Oct;299(17):915-919.

21. Glew RH, Moellering RC Jr, Burke JF. Gentamicin dosage in children with extensive burns. J Trauma 1976 Oct;16(10):819823.

22. MacLennan N, Heimbach DM, Cullen BF. Anesthesia for major thermal injury. Anesthesiology 1998 Sep;89(3):749-770.

23. Gronert GA, Schaner PJ, Gunther RC. Multiple halothane anesthesia in the burn patient. JAMA 1968 Sep;205(12):878880.

24. Demling RH, Ellerbee S, Jarrett F. Ketamine anesthesia for tangential excision of burn eschar: a burn unit procedure. J Trauma 1978;18:267-270.

25. Tai-Kyung S, Jin-Kyu L, EunKyung Y. Propofol-ketamine or propofol-remifentanil for deep sedation and analgesia in pediatric patients undergoing burn dressing changes: a randomized clinical trial. Pediatric Anesthesia 2014 Dec 30. doi: http:// dx.doi.org/10.1111/pan.12592.. [Epub ahead of print].

26. Yamashita S, Kaneda K, Han TH. Population pharmacokinetics of a propofol bolus administered in patients with major burns. Burns 2010 Dec;36(8):1215-1221.

27. Han TH, Greenblatt DJ, Martyn JA. Propofol clearance and volume of distribution are increased in patients with major burns. J Clin Pharmacol 2009 Jul;49(7):768-772.

28. Han TH, Lee JH, Kwak IS et al. The relationship between bispectral index and targeted propofol concentration is biphasic in patients with major burns.
Acta Anaesthesiol Scand 2005 Jan;49(1):85-91.

29. Kaneda K, Han TH. Comparative population pharmacokinetics of fentanyl using non-linear mixed effect modeling: burns vs non-burns. Burns 2009 Sep;35(6):790-797.

30. Saffle JR, Sullivan JJ, Tuohig GM et al. Multiple organ failure in patients with thermal injury. Crit Care Med 1993 Nov;21(11):1673-1683.

31. Martyn JA, Szyfelbein SK, Ali $\mathrm{HH}$ et al. Increased d-tubocurarine requirement following major thermal injury. Anesthesiology 1980 Apr;52(4):352-355.

32. Dwersteg JF, Pavlin EG, Heimbach DM. Patients with burns are resistant to atracurium. Anesthesiology 1986 Nov;65(5):517-520.

33. Schaner PJ, Brown RL, Kirksey TD et al. Succinylcholineinduced hyperkalemia in burned patients. 1. Anesth Analg 1969 Sep-Oct;48(5):764-770.

34. Martyn JA, Szyfelbein SK, Ali $\mathrm{HH}$ et al. Increased d-tubocurarine requirement following major thermal injury. Anesthesiology 1980 Apr;52(4):352-355.

35. Martyn J. Clinical pharmacology and drug therapy in the burned patient. Anesthesiology 1986 Jul;65(1):67-75.

36. Ibenbunjo C, Martyn J. Force, fatigue and sensitivity to dTubocurarine after burn injury in the rat. Anesthesiology 1997;87 Supplement:A859.

37. Martyn JA, Matteo RS, Szyfelbein SK et al. Unprecedented resistance to neuromuscular blocking effects of metocurine with persistence after complete recovery in a burned patient. Anesth Analg 1982 Jul;61(7):614-617.

38. MacLennan N, Heimbach DM, Cullen BF. Anesthesia for major 
thermal injury. Anesthesiology 1998 Sep;89(3):749-770.

39. Mills AK, Martyn JA. Evaluation of atracurium neuromuscular blockade in paediatric patients with burn injury. Br J Anaesth 1988 Mar;60(4):450455.

40. Mills AK, Martyn JA. Neuromuscular blockade with vecuronium in paediatric patients with burn injury. Br J Clin Pharmacol 1989 Aug;28(2):155-159.

41. Badetti C, Manelli JC. [Curare and burns]. Ann Fr Anesth Rea$\operatorname{nim}$ 1994;13(5):705-712.

42. Martyn J, Goldhill DR, Goudsouzian NG. Clinical pharmacology of muscle relaxants in patients with burns. J Clin Pharmacol 1986 NovDec;26(8):680-685.

43. Aulick LH, Wilmore DW, Mason AD Jr, Pruitt BA Jr. Depressed reflex vasomotor control of the burn wound. Cardiovasc Res 1982 Mar;16(3):113-119.

44. Martyn JA, White DA, Gronert GA et al. Up-and-down regulation of skeletal muscle acetylcholine receptors. Effects on neuromuscular blockers. Anesthesiology 1992 May;76(5):822-843.

45. Tsuneki H, Salas R, Dani JA. Mouse muscle denervation increases expression of an alpha7 nicotinic receptor with unusual pharmacology. J Physiol 2003 Feb;547(Pt 1):169-179.

46. Jeevendra Martyn JA, Fukushima Y, Chon JY et al. Muscle relaxants in burns, trauma, and critical illness. Int Anesthesiol Clin 2006;44(2):123-143.

47. Kim C, Fuke N, Martyn JA. Burn injury to rat increases nicotinic acetylcholine receptors in the diaphragm. Anesthesiology 1988 Mar;68(3):401-406.

48. Hartzell HC, Fambrough DM.
Acetylcholine receptors. Distribution and extrajunctional density in rat diaphragm after denervation correlated with acetylcholine sensitivity. J Gen Physiol 1972 Sep;60(3):248-262.

49. Eldridge L, Liebhold M, Steinbach JH. Alterations in cat skeletal neuromuscular junctions following prolonged inactivity. $\mathrm{J}$ Physiol 1981;313(1):529-545.

50. Witzemann V, Brenner HR, Sakmann B. Neural factors regulate $\mathrm{AChR}$ subunit mRNAs at rat neuromuscular synapses. J Cell Biol 1991 Jul;114(1):125-141.

51. Ward JM, Rosen KM, Artyn JA. Acetylcholine receptor subunit mRNA changes in burns are different to that seen after denervation. J Burn Care Rehabil 1993;14:595-601.

52. Green WN, Ross AF, Claudio T. Acetylcholine receptor assembly is stimulated by phosphorylation of its $\gamma$ subunit. Neuron 1991 Oct;7(4):659-666.

53. Martyn J. Clinical pharmacology and drug therapy in the burned patient. Anesthesiology 1986 Jul;65(1):67-75.

54. Han TH, Yamashita S. Vecuronium Pharmacokinetics in Major Burns. Anesthesiology 2010; A882.

55. Piafsky KM, Borgá O, Odar-Cederlöf I et al. Increased plasma protein binding of propranolol and chlorpromazine mediated by disease-induced elevations of plasma alpha1 acid glycoprotein. N Engl J Med 1978 Dec;299(26):1435-1439.

56. Leibel WS, Martyn JA, Szyfelbein SK et al. Elevated plasma binding cannot account for the burn-related d-tubocurarine hyposensitivity. Anesthesiology 1981 May;54(5):378-382.

57. Martyn JA, Abernethy DR, Greenblatt DJ. Plasma protein binding of drugs after severe burn injury. Clin Pharmacol Ther 1984 Apr;35(4):535-539.

58. Wood M, Stone WJ, Wood AJ. Plasma binding of pancuronium: effects of age, sex, and disease. Anesth Analg 1983 Jan;62(1):2932.

59. Storella RJ, Martyn JA, Bierkamper GG. Anti-curare effect of plasma from patients with thermal injury. Life Sci 1988;43(1):35-40.

60. Tomera JF, Martyn J. Mediators of burn-induced neuromuscular changes in mice. Br J Pharmacol 1989 Nov;98(3):921-929.

61. Hagen J, Martyn J, Szyfelbein SK et al. Cardiovascular and neuromuscular responses to high-dose pancuronium-metocurine in pediatric burned and reconstructive patients. Anesth Analg 1986 Dec;65(12):13401344.

62. Martyn JA, Liu LM, Szyfelbein SK et al. The neuromuscular effects of pancuronium in burned children. Anesthesiology 1983 Dec;59(6):561-564.

63. Dwersteg JF, Pavlin EG, Heimbach DM. Patients with burns are resistant to atracurium. Anesthesiology 1986 Nov;65(5):517-520.

64. D'Eramo C, Lombardelli L, Lunardi S. [Severely burned patients and atracurium: the train-of-four response]. Cah Anesthesiol 1992;40(5):333-336.

65. Mills A, Martyn JA, Szyfelbein SK. Electromyographic studies of patients with termal injury. Anesthesiology 1986; A294.

66. Lennon RL, Olson RA, Gronert GA. Atracurium or vecuronium for rapid sequence endotracheal intubation. Anesthesiology 1986 Apr;64(4):510-513.

67. Vega-Villa KR, Kaneda K, Yamashita S et al. Vecuronium 
Consideraciones farmacológicas en el manejo anestésico del paciente quemado - R. Bustamante B. et al.

pharmacokinetics in patients with major burns. Br J Anaesth 2014 Feb;112(2):304-310.

68. Kamolz LP, Andel H, Greher $\mathrm{M}$ et al. Serum cholinesterase activity reflects morbidity in burned patients. Burns 2002 Mar;28(2):147-150.

69. Han TH, Martyn JA. Neuromuscular pharmacodynamics of mivacurium in adults with major burns. Br J Anaesth 2011 May;106(5):675-679.

70. Werba AE, Neiger FX, Bayer GS et al. Pharmacodynamics of mivacurium in severely burned patients. Burns 1996 Feb;22(1):62-64.

71. Han TH, Martyn JA. Neuromuscular pharmacodynamics of mivacurium in adults with major burns. Br J Anaesth 2011 May;106(5):675-679.

72. Martyn JA, Goudsouzian NG, Chang Y et al. Neuromuscular effects of mivacurium in 2- to 12-yr-old children with burn injury. Anesthesiology 2000 Jan;92(1):31-37.

73. Martyn JA, Chang Y, Goudsouzian NG et al. Pharmacodynamics of mivacurium chloride in 13- to 18-yr-old adolescents with thermal injury. Br J Anaesth 2002 Oct;89(4):580-585.

74. Han T, Kim H, Bae J et al. Neuromuscular pharmacodynamics of rocuronium in patients with major burns. Anesth Analg 2004 Aug;99(2):386-392.

75. Mort TC. Preoxygenation in critically ill patients requiring emergency tracheal intubation. Crit Care Med 2005 Nov;33(11):2672-2675.

76. Han TH, Martyn JA. Onset and effectiveness of rocuronium for rapid onset of paralysis in patients with major burns: priming or large bolus. Br J Anaesth 2009 Jan;102(1):55-60.
77. Allan CM, Cullen WG, Gillies DM. Ventricular fibrilation in a burned boy. Can Med Assoc J 1961 Aug;85:432-434.

78. Belin RP, Karleen CI. Cardiac arrest in the burned patient following succinyldicholine administration. Anesthesiology 1966 Jul-Aug;27(4):516-518.

79. Schaner PJ, Brown RL, Kirksey TD et al. Succinylcholineinduced hyperkalemia in burned patients. 1. Anesth Analg 1969 Sep-Oct;48(5):764-770.

80. Gronert GA. Succinylcholine hyperkalemia after burns. Anesthesiology 1999 Jul;91(1):320-322.

81. Gronert GA. Succinylcholine hyperkalemia after burns. Anesthesiology 1999 Jul;91(1):320-322.

82. MacLennan N, Heimbach DM, Cullen BF. Anesthesia for major thermal injury. Anesthesiology 1998 Sep;89(3):749-770.

83. Paladino M, Tomiello F. Anestesia en el Quemado de Alto Riesgo. Rev Arg Anest 1998;56:111139.

84. Fung DL, White DA, Jones BR et al. The onset of disuse-related potassium efflux to succinylcholine. Anesthesiology 1991 Oct;75(4):650-653.

85. Brown TC, Bell B. Electromyographic responses to small doses of suxamethonium in children after burns. Br J Anaesth 1987 Aug;59(8):1017-1021.

86. Nosek MT, Martyn JA. Na+ channel and acetylcholine receptor changes in muscle at sites distant from burns do not simulate denervation. J Appl Physiol (1985) 1997 Apr;82(4):13331339.

87. Martyn JA, Richtsfeld M. Succinylcholine-induced hyperkalemia in acquired pathologic states: etiologic factors and molecular mechanisms. Anesthesiology 2006 Jan;104(1):158-169.
88. Yentis SM. Suxamethonium and hyperkalaemia. Anaesth Intensive Care 1990 Feb;18(1):92-101.

89. Martyn JA, Szyfelbein S, Sheridan $\mathrm{R}$ et al. Burned patients are not resistant to the Neuromuscular effects of Mivacurium. Anesthesiology 1997;87 Supplement:A862.

90. Segredo V, Caldwell JE, Matthay MA et al. Persistent paralysis in critically ill patients after long-term administration of vecuronium. N Engl J Med 1992 Aug;327(8):524-528.

91. Kupfer Y, Namba T, Kaldawi E et al. Prolonged weakness after long-term infusion of vecuronium bromide. Ann Intern Med 1992 Sep;117(6):484-486.

92. Merriman HM. The techniques used to sedate ventilated patients. A survey of methods used in 34 ICUs in Great Britain. Intensive Care Med 1981;7(5):217224.

93. Appadu BL, Greiff JM, Thompson JP. Postal survey on the long-term use of neuromuscular block in the intensive care. Intensive Care Med 1996 Sep;22(9):862-866.

94. Bustamante R. Bloqueadores neuromusculares en cuidados intensivos. Rev Chil Anest 2004;33:147-174.

95. Segredo V, Caldwell JE, Matthay MA et al. Persistent paralysis in critically ill patients after long-term administration of vecuronium. N Engl J Med 1992 Aug;327(8):524-528.

96. Miller RD, Savarese JJ. Pharmacology of muscle relaxants and their antagonists. En: Anesthesia. RD Miller. Churchill Livingstone; 5 th edition (January 15, 2000): 427.

97. Dodson B, Kelly B, Bruswell L et al. Long-term high dose muscle relaxant causes up-regulation 
of Acetylcholine receptors in critically ill adults. Anesthesiology 1993;79:A292.

98. Yáñez P, Martyn JA. Prolonged d-tubocurarine infusion and/or immobilization cause upregulation of acetylcholine receptors and hyperkalemia to succinylcholine in rats. Anesthesiology 1996 Feb;84(2):384-391.

99. Shapiro BA, Warren J, Egol AB et al. Society of Critical Care Medicine. Practice parameters for sustained neuromuscular blockade in the adult critically ill patient: an executive summary. Crit Care Med 1995 Sep;23(9):1601-1605.

100. Suppini A, Kaiser E, Sallaberry
$\mathrm{M}$ et al. Use of neuromuscular blocking agents in intensive therapy practice. Ann Fr Anesth Reanim 1999;18:341.

101. Topulos GP, Lansing RW, Banzett RB. The experience of complete neuromuscular blockade in awake humans. J Clin Anesth 1993 Sep-Oct;5(5):369-374.

102. Boyd AH, Eastwood NB, Parker CJ et al. Comparison of the pharmacodynamics and pharmacokinetics of an infusion of cis-atracurium (51W89) or atracurium in critically ill patients undergoing mechanical ventilation in an intensive therapy unit. Br J Anaesth 1996 Mar;76(3):382-388.
103. Lagneau F, D'honneur G, Plaud $B$ et al. A comparison of two depths of prolonged neuromuscular blockade induced by cisatracurium in mechanically ventilated critically ill patients. Intensive Care Med 2002 Dec;28(12):1735-1741.

104. American College of Critical Care Medicine of the Society of Critical Care Medicine, American Society of Health-System Pharmacists, American College of Chest Physicians. Clinical practice guidelines for sustained neuromuscular blockade in the adult critically ill patient. Am J Health Syst Pharm 2002 Jan;59(2):179-195. 